\title{
Granada Arap Çalışmaları Enstitüsü
}

\author{
FATMA MERVE ÇETINEL
}

Ankara Üniv. İlahiyat Fakültesi

mervecetinel@gmail.com

İspanya'da İslâm tarihi ve medeniyeti, dokuz yüzyıllık Endülüs tecrübesinin de etkisiyle, 18. yüzyıldan itibaren, akademik açıdan önem arz eden bir çalışma sahası hâline gelmiştir. Bu bağlamda, İslâm tarihi ve medeniyeti alanında akademik araştırmalar yapmak, lisans ve lisansüstü eğitim vermek amacıyla çeşitli üniversitelerde Arap ve İslâm çalışmaları bölümleri ile bağımsız enstitüler kurulmuştur. Örnek olarak, Alicante, Cadíz, Córdoba, Granada, Málaga, Valencia, Zaragoza, Madrid Complutense ve Madrid Autonoma Üniversitelerinin Arap ve İslâm Çalışmaları bölümleri (Departamento Estudios Àrabes e Islàmicos) bulunmaktadır. Bunun yanı sıra, Mısır Enstitüsü (Instituto Egipcio), Arap Evi (Casa Àrabe), İspanyol Arap Çalışmaları Merkezi (Sociedad Española de Estudios Árabes), Yaşayan Endülüs Kütüphanesi (Biblioteca Viva de Al-Andalus) gibi bağımsız enstitü ve kurumlar bünyesinde de İslâm tarihi ve medeniyeti, Endülüs tarihi gibi alanlarda muhtelif çalışmalar yapılmakta; çeşitli sempozyum, konferans, seminer ve Arapça dil kursları düzenlenmekte ve projeler hazırlanmaktadır.

Yukarıda zikredilen ve İslâm çalışmaları alanında etkinlik gösteren bölümleri ve enstitüler arasında, tanıtımı yapılacak olan, Granada Arap Çalışmaları Enstitüsü'nün ${ }^{1}$ (Escuela de Estudios Àrabes de Granada), sahasındaki bilimsel yetkinliği ve zenginliği açısından ayrı bir yeri bulunmaktadır.

İspanya'nın Granada kentinde bulunan Arap Çalışmaları Enstitüsü, İspanyol Yüksek Bilim Araştırma Konseyi'nin (Consejo Superior de Investigaciones Cientìficas de España-CSIC), İspanya Ekonomi ve Rekabet Bakanlığı'na (Ministerio de Economìa y Competitividad) bağlı olarak, Endülüs tarihi ve medeniyeti özelinde İslâm tarihi ve kültür hayatına dair araştırmalar yapan bir enstitüsüdür.

\section{Tarihçe}

4 Şubat 1932'de, Madrid Gazetesi'nde (Gaceta de Madrid) yayımlanan kanun ile İspanya'daki Madrid Arap Çalışmaları Okulu ve Granada Arap Çalışmaları Okulu eş zamanlı olarak kurulmuştur. ${ }^{2}$ Kanunda belirtilen amaç, farklı kelimelerle

\footnotetext{
${ }^{1}$ Enstitü'nün adında yer alan Arap Çalışmaları (Estudios Àrabes) kavramı, İslâm çalışmaları anlamını taşımaktadır. Kurumun isminde herhangi bir değişiklik yapmamak adına, Granada Arap Çalışmaları Enstitüsü şeklinde tercüme edilmiştir.

${ }^{2}$ Camilo Âlvarez de Morales, http://www.eea.csic.es/index.php?option=com_content\&task=view\&id=14\&Itemid=27 (04.06.2013).
} 
de olsa, okulların kuruluş tüzüklerine de yansımıştır. Nitekim ünlü İspanyol oryantalist Emilio Garcia Gòmez'in (1905-1995) gayretleriyle açılan Granada Arap Çalışmaları Okulu, amacını "bilimsel araştırmalar eşliğinde, Arap dilini ve İslâm medeniyetini yüksek seviyede öğretmek”, Miguel Asin Palacios (1871-1944) başkanlığında kurulan Madrid Arap Çalışmaları Okulu ise "İslâm toplumu, medeniyeti ve tarihi alanında yapılan çalışmaları desteklemek ve denetlemek"3 biçiminde ifadelendirmiştir.

Emilio Garcìa Gòmez, ${ }^{4}$ 20. yüzyılın ilk İspanyol oryantalistlerdendir. Önce Madrid Complutense Üniversitesi'nde, 1930'dan itibaren de Granada Üniversitesi'nde Arap Dili profesörü olarak görev yapmış, Madrid Arap Çalışmaları Okulu, hocası Miguel Asin Palacios tarafından kurulurken, kendisi de Granada Arap Çalışmaları Okulu'nun kuruculuğunu üstlenmiştir.

Granada Arap Çalışmaları Okulu'nun kuruluşunda belirlenen amaca yönelik olarak, Arapça, İbranice, siyasî ve kültürel İslâm tarihi ile İslâm kurumları ve İslâm hukuku dersleri verilmeye başlanmış; kurum bünyesinde yapılan çalışmalar, $A l$ Andalus: Revista de las Escuelas de Estudios Àrabes de Madrid y Granada (Endülüs: Madrid ve Granada Arap Çalışmaları Okulu Dergisi) adıyla, 1933-1978 yılları arasında Madrid ve Granada'da basılan akademik dergide yer almıştır. ${ }^{5} \mathrm{Al}$ Andalus dergisi, 1979 yllından itibaren, CSIC bünyesinde Al-Qantara: Revista de Estudios Árabes ${ }^{6}$ ismiyle çıkmaya devam etmektedir.

Granada'daki Arap Çalışmaları Okulu'nun ayırt edici özelliklerinden biri de Arap ülkelerinden gelen öğrenci ve araştırmacıları burslarla desteklemesidir. Özellikle Fas’tan gelen öğrencilerin, İspanyol araştırmacılarla bir arada çalışması, İslâm tarihi genelinde ve Endülüs tarihi özelinde yapılan çalışmalarda, akademik paylaşımın artmasını sağlamıştır.

Granada Arap Çalışmaları Okulu, Emilio Garcìa Gòmez başkanlığında kurulduğunda, şu dört bilim dalında çalışmalar yürütülmekteydi:

- Arapça-İbranice Filolojisi ve Edebiyatı

- İslâm Hukuku ve Kurumları

- Siyâsî ve Kültürel İslâm Tarihi

- İslâm Sanatı ve Arkeolojisi ${ }^{7}$

1936 yılına kadar, söz konusu bilim dalları altında araştırmalar yapılmış, geniş bir kütüphane kurulmuş; seminerler, konferanslar ve alana yönelik kurslar

\footnotetext{
${ }^{3}$ Camilo Àlvarez de Morales, http://www.eea.csic.es/index.php?option=com content\&task=view\&id=14\&Itemid=27 (04.06.2013).

${ }^{4}$ H. Adil Kamal, "El Arabista Emilio García Gómez: Su Vida," Journal of College of Languages (Baghdad) 22 (2010), s.219.

${ }^{5}$ Bkz. http://dialnet.unirioja.es/servlet/revista?codigo=9439 (04.06.2013).

${ }^{6} \mathrm{Bkz}$. http://al-qantara.revistas.csic.es/index.php/al-qantara (04.06.2013).

${ }^{7}$ Estanislao Maestre (ed.), Escuela de Estudios Árabes de Granada (Casa del Chapiz): Curso 1934-1935 (Granada, 1934), s.8.
} 
düzenlenmiş, arkeolojik kazılar yapılmış ve başarılı araştırmacılar ödüllendirilmiştir. ${ }^{8}$

1936 yılında İspanya İç Savaşı'nın başlaması ve Emilio Garcìa Gòmez’in Madrid'e dönmesi, kurumun çalışmalarını olumsuz yönde etkilemiştir. Üç yıl süren İspanyol İç Savaşı'nın 1939'da sona ermesinin ardından, Granada Arap Çalışmaları Okulu, ülke çapında bilimsel faaliyetleri düzenlemek amacıyla kurulan İspanya Yüksek Bilimsel Araştırma Konseyi (CSIC) bünyesine katılmış; böylece çeşitli enstitülerden oluşan CSIC çatısı altında müstakil bir enstitü olarak çalışmalarına devam etmiştir. ${ }^{9}$

1979 yılına kadar Granada Arap Çalışmaları Enstitüsü’nün bağlı bulunduğu ve Enstitü'yü maddî olarak destekleyen kurumlar her ne kadar değişmiş olsa da nihayet 1979'da CSIC, Enstitü'nün akademik personeline maddî destek sağlayarak, üniversitelerden bağımsız bir kurum hâline gelmesini sağlamıştır. Bu nihâî yapı ile birlikte Granada Arap Çalışmaları Enstitüsü, Ortaçağ İspanyasında Müslüman mirası, İslâm kültür ve medeniyeti, Endülüs tarihi, mimarîsi, sanatı, doğa bilimleri ile Moriskolar gibi konular üzerindeki araştırmalara yoğunlaşmıştır. Böylece, araştırma sahası genişletilerek, İspanya'da dokuz yüzyıllık İslâm tecrübesinin farklı bakış açıları ve yöntemlerle değerlendirilmesi hedeflenmiştir. 1990'lı yıllardan itibaren Enstitü Kütüphanesi, Arap ve İslâm çalışmaları alanında ülkenin en önde gelen kurumları arasına girecek ölçüde zenginleştirilmiştir. ${ }^{10}$ Enstitü, 1932'de kurulduğu günden beri, Granada'da, 14. yüzyıldan kalma bir Endülüs mimarîsi örneği olan Casa Del Chapiz'de faaliyet göstermektedir.

\section{Günümüzde Granada Arap Çalışmaları Enstitüsü}

Granada Arap Çalışmaları Enstitüsü'nün günümüzde en temel amacı, genelde İslâm tarihi ve medeniyeti, özelde ise Endülüs kültürü, tarihi ve medeniyeti hakkında araştırmalar yapmaktır. Enstitü'nün tek çatı altında ve dört araştırma alanında faaliyet gösterdiği söylenebilir. Bunlar:

- Endülüs’te doğa bilimleri

- Endülüs toplumu ve sosyal hayatı

- Endülüs mimarîsi

- Ortaçağ İslâm tarihi, arkeolojisi ve Endülüs kültürel mirasının korunmasidır. ${ }^{11}$

$\mathrm{Bu}$ araştırma alanları içerisinde, Enstitü’nün simgesi hâline gelen çalışmalar, Endülüs Tarihi, Arapça yazmaların edisyon ve tercümesi, Granada Müslümanları ve Moriskolar tarihi, Endülüs dönemi arkeoloji araştırmaları, Arapça biyografi

\footnotetext{
${ }^{8}$ Maestre (ed.), Escuela de Estudios Árabes de Granada, s.9.

${ }^{9}$ Camilo Àlvarez de Morales,

http://www.eea.csic.es/index.php?option=com content\&task=view\&id=14\&Itemid=27 (04.06.2013).

${ }^{10}$ Juan Castilla Brazales, "La Escuela de Estudios Àrabes en su 75 Aniversario," Awraq 23 (2006), s.294.

${ }^{11}$ Brazales, "La Escuela de Estudios Àrabes en su 75 Aniversario," s.295.
} 
(tabakât-terâcim) kaynakları, Endülüs dönemi doğa bilimleri, İslâm hukuku, İslâm kurumları yer almaktadir.

Granada Arap Çalışmaları Enstitüsü, CSIC’in diğer enstitüleri ile -özellikle Filoloji ve Tarih Enstitüleri- sıkı bir akademik ilişki içerisindedir. Aynı şekilde başta Granada Üniversitesi olmak üzere, diğer İspanyol üniversiteleri ve ulusaluluslararası organizasyonlarla ortak çalışmalar yürütmekte, yüksek lisans ve doktora öğrencilerine yönelik kredili dersler ve dönemlik kurslar verip, çeşitli seminer, sempozyum ve konferanslar düzenlemektedir. Enstitü direktörlüğünü 2005 y1lından beri Juan Castilla Brazales yürütmektedir.

\section{Granada Arap Çalışmaları Enstitüsü Kütüphanesi}

Endülüs ile ilgili akademik çalışmalar esnasında başvurulabilecek en geniş kütüphanelerden biridir. Halka açık bir kütüphanedir, fakat kütüphaneyi kullanmak için üye olmak gerekiyor. CSIC bünyesinde faaliyet gösteren diğer tüm kütüphanelerle birlikte oluşturulmuş ortak tarama motoru üzerinden arama yapılabildiği gibi, bu yolla tam erişime açık eserler de bulunmaktadır. ${ }^{12}$

Kütüphane koleksiyonu, İslâm tarihi ve medeniyeti ile özellikle Endülüs'ü konu edinen on yedi bin cildi aşkın kitap ve yüzden fazla süreli yayından oluşmaktadır. ${ }^{13}$

Enstitüye ait yazmalar arşivi ise toplam altmış ciltten oluşmaktadır. Enstitü kütüphanesinden ayrı olarak CSIC tarafından, İbranîce ve Arapça arşiv belgelerinin internet ortamında erişimi de mümkün hâle getirilmiştir. ${ }^{14}$

Kütüphanede Arapça arşiv belgeleri, yazma ve araştırma eserlerinin yanı sıra, Miladî 15 ve 16. yüzyıl gibi erken dönem İspanyol oryantalizmine ait örnek eserler de yer almaktadir. ${ }^{15}$

\section{Granada Arap Çalışmaları Enstitüsü Bünyesinde Yürütülmekte Olan Araştırma Projeleri ${ }^{16}$}

1. Endülüs Yerleşim Alanlar Mimarisi: Tipolojik, Sosyolojik ve Kentsel Bağlamda Analizi ve Kültürel Mirasa Müdahalenin Temelleri (2011-2014)

$\mathrm{Bu}$ proje, öngörülen üç yılık süre zarfinda, yapılacak arkeolojik kazılar ve araştırmalar 1şı̆̆ında, Endülüs dönemi şehir yaşamının tespiti ve tahlili amacını taşımaktadır. İncelenecek yerleşim alanları ve yapılar, tüm yönleriyle ele alınıp bunların kent yaşamıyla ilişkisi sosyolojik boyutlarıyla değerlendirilmektedir.

\footnotetext{
${ }^{12}$ Katalog taraması için bkz.

http://aleph.csic.es/F/CFKCI56AIESDUBEHRNXIAH464DY4UCEJLN5MVDG3BEPBN57PI650862?RN=267577471\&pds handle=GUEST (04.06.2013). Tam erişimine izin verilen arşiv belgeleri, el yazmaları ve araştırmalar için bkz. http://digital.csic.es/ (04.06.2013).

${ }^{13} \mathrm{http}: / /$ www.eea.csic.es/index.php?option=com content $\&$ task=view\&id=101\&Itemid=50\&lang=es (04.06.2013)

${ }^{14}$ Bkz. http://manuscripta.bibliotecas.csic.es/ (04.06.2013).

${ }^{15} \mathrm{http}: / / \mathrm{www}$. eea.csic.es/index.php?option=com content\&task=view\&id=101\&Itemid=50 $(04.06 .2013)$.

16 Araştıma projeleri hakkında ayrıntılı bilgi için bkz.

http://www.eea.csic.es/index.php?option=com_content\&task=view\&id=76\&Itemid=42 (04.06.2013).
} 
Endülüs mimarîsinde yaşam alanının özellikleri belirlenecek, Hıristiyan hâkimiyetinin ardından meydana gelen değişiklikler tespit edilip bu farklılaşmanın, Endülüs tarzı özel ve sosyal yaşama etkisi üzerinde durulacaktır.

2. Endülüs Dönemi Nasrî Şehirleri: Kentsel Düzen, Savunma Sistemi ve Şehir Suyu Tedârik Yöntemleri (2011-2014)

Granada Nasrî Sultanlığı (1232-1492) devrine ilişkin bilimsel araştırmalar her ne kadar söz konusu dönemi siyasî, sosyal, ekonomik, kültürel ve dinî açıdan ele almış olsa da, Nasrî şehirlerine ve şehrin sosyolojik-mimarî yapısına vurgu yapan araştırmalar, diğerlerine göre oldukça azdır. Bu bağlamda üç yıllık bir sürede gerçekleştirilecek olan bu proje, bahsedilen boşluğu doldurma amacını taşımaktadır. Proje kapsamında, Nasrî Sultanlığı egemenliğinde yaklaşık iki buçuk yüzyıl geçirmiş olan Granada, Màlaga, Cadíz, Almeria gibi İspanya'nın güney şehirlerinde arkeolojik kazılar yapılmaktadır. İspanyol mimarî ve arkeoloji laboratuarlarında geliştirilen yeni teknikler ile zikredilen şehirlerde elde edilecek bulgular değerlendirilecektir.

Şehirlerin sosyal, askerî ve siyasal hayatta oynadıkları role vurgu yapan bu proje, tıpkı diğerleri gibi yalnızca saha çalışmasıyla sınırlı kalmayıp konuya ilişkin tarihî verilerin, metinlerin yazmaların, harita ve görsel malzemenin de dâhil edilmesiyle zenginleştirilmektedir. Ayrıca yukarıda ismi geçen her şehrin, Nasrî Sultanlık dönemine ait birer tarihî kentsel planının çıkarılması ve bu tarihî mirasın daha bilinçli bir şekilde korunması hedeflenmektedir.

\section{Endülüslü Âlimler Ansiklopedisi (2010-2013)}

Bu proje kapsamında, 13-15. yüzyılları arasında İspanya'da yaşayan Endülüslü âlimlerin biyografileri, tarihî kaynaklara dayanılarak derlenip basılacaktır. Böylece, söz konusu tarih aralı̆̆ında yaşamış Endülüslü âlimlerin, döneme ait tabakât ve terâcim eserlerinde yer alan biyografileri bir araya getirilecektir.

\section{Endülüs'te Tarım ve Orman Arazileri (2010-2013)}

Projenin amacı, Endülüs dönemi tarım ve ormanlık alanların tespiti ve analizidir. Proje sonunda, Endülüs bölgesinde yetișen ve günümüzde tespit edilebilen bitkilerin tümünü içeren bir katalog hazırlanması hedeflenmektedir. Ayrıca, insan müdahalesi ve iklim değişikliği ile birlikte, Endülüs döneminden günümüze, tarım arazilerin, ormanlar ve bitki örtüsünde meydana gelen farklılaşma ortaya konacaktır.

\section{Granada Nasrî Sultanlığı Dönemi Mahkeme Kayıtları (2010-2013)}

Daha önce aynı konuda yapılmış benzer projelerin devamı niteliğinde olan bu çalışma, diğerlerinden farklı olarak Endülüs genelinden ziyade Nasrî dönemi özelinde mahkeme kayıtları ve hukukî düzenlemeler üzerinde yoğunlaşmaktadır. 


\section{Enstitü Yayınları}

Granada Arap Çalışmaları Enstitüsü, araştırmacıların müstakil çalışmalarının yanı sıra, seri araştırma kitapları da yayınlamaktadır. Daha önce bahsedildiği gibi, CSIC bünyesinde Granada Arap Çalışmaları Enstitüsü adına Al-Qantara dergisi yayın hayatını sürdürmektedir.

Enstitü'nün yayınlamakta olduğu kitap serileri şu şekildedir:

- $\quad$ Arap ve İslâm Çalışmaları: Monografiler 1. seri (30 cilt ) ve 2. seri (19 cilt)

- $\quad$ Endülüs’te Doğa Bilimleri Serisi (8 cilt)

- $\quad$ Endülüs Biyografi Serisi (18 cilt)

- $\quad$ Endülüs Kaynaklar Koleksiyonu (32 cilt)

Granada Arap Çalışmaları Enstitüsü, yukarıda zikredilen kitap serileri ile başta Endülüs tarihi olmak üzere, tıp ve doğa bilimleri, edebiyat, İslâm hukuku gibi alanlarda önem arz eden kaynak eserleri -bir kısmını İspanyolca tercümeleri ile birlikte- yayınlamıştır. ${ }^{17}$ Bunun yanı sıra, Enstitü tarafından sürekli gerçekleştirilmekte olan Endülüs dönemi arkeolojik kazılarının da akademik çalışmalar açısından ayrı bir önemi bulunmaktadır. Enstitü, İspanya'daki İslâm ve Endülüs tarihi çalışmaları açısından, yayınları, projeleri ve akademik kadrosu ile öne çıkmakta, hem ulusal hem de uluslararası düzeyde, dikkatleri Endülüs çalışmalarına çekmeyi başarmaktadır.

\footnotetext{
${ }^{17}$ Enstitü yayınlarının detaylı bilgisi için bkz. http://www.eea.csic.es/index.php?option=com content\&task=view\&id=56\&Itemid=89 $(04.06 .2013)$
} 